\title{
O CLAMOR DA DIFERENÇA LETAL: EDUCAR EM ESTADO DE EXCEÇÃO
}

\author{
Fernando Pocahy (UERJ - Universidade do Estado do Rio \\ de Janeiro / pocahy@uol.com.br)
}

\begin{abstract}
Resumo
O presente ensaio consiste em um testemunho analítico sobre os acontecimentos da política brasileira e fluminense pós-golpe. Em um movimento de reflexividade-ética, examino a repercussão direta da atual razão de estado na prática cotidiana de uma universidade pública. $\mathrm{O}$ tom da narrativa consiste ainda de um clamor face à letalização cotidiana da diferença e seu impacto na agenda de pesquisa. Para isso, em modo autobiográfico, apresento algo dos desafios éticos, estéticos e políticos vivenciados na atual conjuntura. Aliando-me teórico-metodologicamente às cartografias discursivodesconstrucionistas presentes nos estudos trans/feministas e queer, notadamente as apostas pós-críticas dos estudos de gênero e sexualidade em interseccionalidades na educação, localizo meus (des)caminhos para pensar a mim mesmo face ao enquadramento normativo de nossas lutas atuais, tomando as ferramentas do ideal democrático (e sua ampla possibilidade de ampliar seus próprios sentidos) como plataforma de produção da experiência do conhecimento.
\end{abstract}

Palavras-chaves: gênero; estado de exceção; universidade pública

\section{THE CLAMOR OF THE LETAL DIFFERENCE: EDUCATING IN STATE OF EXCEPTION}

\begin{abstract}
The present essay consists of an analytical witness on the events in the Brazilian politics and Rio de Janeiro in the context of the post-coup. In a ethical reflexivity movement, I examine the direct repercussion of the present reason of the state in the everyday manner of a public university. The tone of the narrative still consists in a clamor in face of the everyday life breakdown of the difference and its impact on the research agenda. For this, on autobiographical mode, I present some of the ethical, aesthetic and political challenges experienced in the current conjuncture. While combining myself theoretical-methodologically with the discursive-deconstructionist cartographies present in the (trans)feminist and queer studies, notably the post-critical bets of gender and sexuality studies on intersectionalities in education, I locate my (un)ways to think myself about the normative framework of our current struggles, taking the tools of the democratic ideal(and its huge possibility to extend its own senses) as platform of production of the experience of/in the knowledge.
\end{abstract}

Keywords: gender; state of exception; public university

\section{CLAMORES DO/NO IN-MUNDO}

Quase todos os dias, desde 31 de agosto de 2016, alucino a pior das angústias: nossas esperanças torturadas, nossos sonhos sequestrados, nossos pares exterminados. Corpolíticas que já não mais pode(ria)m existir, algumas delas já não têm mais força pra resistir, combatentes de primeira fila adoecem, padecendo dos efeitos da assunção colonial. Esses 
efeitos não são da ordem da contemplação ou de uma mirada distante. Não, eles estão vivos no meu cotidiano e eu acompanho de muito perto o avançar da tenebrosa marcha do extermínio da propriedade pública, das práticas de esgotamento da luta política e doloroso epistemicídio, bem como, o extermínio de pessoas marcadas na nova ordem da produção global- local da diferença letal. Isso tudo vai deixando marcas profundas e nos coloca em um estado de atenção próximo aquele promovido pelo terrorismo.

As coisas não estão boas para aquelXs ${ }^{1}$ que percebem na democracia participativa e popular um horizonte ético. O projeto cínico de um desgoverno segue à espreita das eleições, deixando um lastro de dúvidas e medo. Mas há algo mais terrível: estamos perdendo nossos pares, vidas de gente que diz da gente: nossXs alunXs, nossXs companheiras de luta, tanta gente por aí. Vidas que nesse exato momento onde se oficializa o estado de exceção brasileiro, a evidenciar renovadas atualizações do ódio colonial, se tornam ainda mais vulneráveis, mais precárias.

Pronuncio-me e testemunho hoje desde o olho do furacão desse novo regime político forjado no mais cínico e desprezível desejo classista, sexista, totalitário e racista. Já há alguns meses sou testemunha e educador assujeitado à brutal marcha e ataque à educação pública e a tudo o que pode dizer-se bem público: a Universidade do Estado do Rio de Janeiro (UERJ), instituição pioneira na implementação da política de cotas e da oferta de cursos noturnos e suas coirmãs (UEZO e UENF) agonizam desde 2015 com o desmonte do financiamento na pesquisa e ensino superior. Foram meses de atrasos em salários e bolsas (como as de permanência), chegando ao limite de três soldos devidos. Houve o fechamento do restaurante universitário e as demais dívidas com empresas terceirizadas (incluindo-se essa, mas sobretudo de conservação, segurança e higienização) acabaram ainda ampliar a soma de violações de direitos: trabalhadorXs já em muito precarizadXs não recebiam seus salários. A política da terceirização esteve (está) mais exposta do que nunca: quase todXs Xs trabalhadorXs eram (são) mulheres negras e em idade de pouca realocação em outros postos de trabalho. Ouso abusar de uma metáfora, talvez a mais próxima do que se vive(u): os

\footnotetext{
${ }^{1}$ Faço uso do sinal « $\mathrm{X} »$ como sinal a colocar sob rasura as noções consagradas e inflexões binárias de gênero. O sinal de sob rasura se justifica aqui no sentido de informar que certos conceitos, expressões, noções "não servem mais - não são mais 'bons para pensar' - em sua forma original, não reconstruída.” (Hall, 2000: 104). Portanto, mais do que fazer caber múltiplos gêneros ou posições de sexualidade através de sinais como o próprio $\mathrm{X}$ ou @, *,\#,_, 'e', etc. tento aqui informar que há um problema de gênero na gramática. Não se trata de uma forma inclusiva, embora guarde essa potencialidade, mas justamente de expor que a linguagem não somente é arena de disputa, mas campo por onde se produz e se marca a diferença.
} 
elevadores da universidade (prédio de 12 andares), assim como os camburões da polícia, guarda(va)m um pouco / ou muito dos navios que traziam povos escravizados há mais de 500 anos.

O Estado do Rio de Janeiro parece um campo de extermínio a céu aberto. Não há que se enganar, não há balas perdidas por aqui, elas são seletivas, escolhem quem matar: pretXs, pobres, moradores de comunidades precarizadas. Ensaio de uma ditadura é Brasil laboratório da privataria e do racismo neoliberal. Chegamos ao esgotamento, à política de exceção, ao estado legalizado de uma necroCORpolítica (fundamentada em uma história colonial brutal).

Assassinaram Marielle Franco e com ela muitos dos sonhos de vermos a vida pulsando de outra forma na política parlamentar, de ver toda uma gente resistindo em outro modo de fazer política e de viver os sentidos do político (Mouffe, 2003). Perdemos a jovem Shellida Ayana, estudante de pedagogia da UERJ, uma mulher trans, negra, jovem, moradora de Mesquita, na baixada fluminense, exterminada pela negligência do estado face à saúde pública, face à efetiva garantia de direitos humanos. Morreu de pneumonia. A ela, mais uma vez, presto minha homenagem, nesta textura-testemunho. Bruno Alves e Matheusa Passareli também foram exterminados, ambXs jovens negrXs, estudantes de cursos de formação docente na UERJ.

Não parece nada razoável perdermos em nossa Universidade três jovens estudantes cotistas em menos de seis meses no ano de 2018. Não parece ainda razoável não reconhecer que eram três jovens ativistas, ambXs em franco enfrentamento às violações dos direitos na interseção de gênero, raça, classe. O clamor marcado nos corpos dessXs jovens revela que agonística da democracia é antes de tudo marcada pelo gênero, sexualidade, raça, multiplicidade de formas de ser e habitar a polis. Corpocidade devastada, corpolítica da diferença letalizada.

Vivemos tempo marcado pelo ódio consentido, autorizado e incitado por (des)governantes - tempo-discurso que fere e posiciona a diferença como o signo material da morte. Diferença letalizada, tomando o corpo como campo de batalha. Máquina-de-morte social, máquina-cancro - necropolítica (Mbembe, 2016). Nada além da pele, tudo está exposto: ex posto, democracia ex posta. Dilma deposta. Democracia deposta. Lula preso. Restam apenas os temerosos lacaios nos centros de decisão molar e a nossa luta nas/das ruas micropolíticas da resistência. 
Estou em luto e estou em luta. Sinto-me (a mim e na direção dX outrX) torturado pela crueldade de um estado cada vez mínimo em sua dimensão de laço e do esvaziamento da propriedade social (Castel, 1997), cada vez maior em sua vontade de fazer morrer, para alguns privilegiados deixar viver. Sigo convencido de que essas práticas políticas da vida institucional e cotidiana sobre as quais estou falando não estão tomando de assalto a vida somente em nosso país. Somos apenas mais um ponto nessa trama complexa que se expande pelo globo - verdadeira episteme de ódio fundamentada em explícito racismo e (hetero)cisnormatividade ${ }^{2}$. Para mim, este é o novo enquadramento do capitalismo mundial, as novas grades para a apreensão política do corpo.

Por isso, cabe salientar, nossos problemas não são problemas isolados. Eles movimentam-se na esfera mundial, agenciando redes de subjetividades. Mas é preciso sublinhar que essas práticas de extermínio não atingem a todas da mesma forma no sistemamundo-global. Elas se valem e se fortalecem através das fraturas mais expostas em cada lugar, região, país, se tecem a partir da cultura do lugar.

Em nosso caso, as paixões tristes e o ódio se alastram pelo tecido social (uma superfície tão complexa quanto impossível de se imaginar), tornando ainda mais frágil e silenciado de qualquer comoção social o insubordinado objeto de extermínio (antecedidos por uma marca de abjeção, exterior constitutivo, o corpo-diferença, aquilo tudo que nos precede).

A hemorragia social mais evidente disso nós acompanhamos com a precarização da vida (Butler, 2005) e quando não menos o extermínio de populações inteiras, seja pela extinção de todo e qualquer direito político e social, seja pela incitação ao genocídio. Entendo que esse é o modo operante de uma individuação emergente que não foi planejada em um núcleo de decisão e controle. Essa prática de marcação do modo indivíduo é produzida em múltiplos cotidianos, em muitas redes e fluxos de subjetivação, contingenciados por uma racionalidade econômica desesperada. Ela não está localizada em um lugar específico, um centro de comando único, mas encontra-se por toda a parte, ressonante em múltiplos complexos de subjetivação e agência.

\footnotetext{
${ }^{2}$ Como afirma Viviane Vergueiro apud Leila Dumaresq (2014) a cisgeneridade pode ser entendida “(...) nomear homenscis, mulheres-cis em oposição a outros termos usados anteriormente como mulher biológica, homem de verdade, homem normal, homem nascido homem, mulher nascida mulher, etc" ( $\mathrm{s} / \mathrm{p})$.
} 
A episteme máquina-de-morte (necropolítica) é a razão de muitos estados face à nova ordem econômica global, agindo de modo específico: vai penetrando e fazendo repercutir de forma molecular o desejo de norma, a individualidade, o ódio à diferença e ao diferir. Seu sintoma histérico, cá pelas nossas bandas tupiniquins, foi dado por um estranho e emblemático gesto: a bateção de panelas, acompanhada de espasmos corporais. Almas amareladas como um grande desejo de senhorio colonial. Normopatia delirante a expor seus efeitos-sintomas em ultraconservadorismo e incitação aos fascismos.

Não tenho dúvida alguma de que os principais efeitos dessa política de morte no Brasil se nutrem do racismo e do heterocisnormatividade, atingindo mais brutalmente populações historicamente subaltenizadas e abjetadas ou aquelas que, se em algum momento de nossa rápida experiência, digamos, inspirada em uma racionalidade econômica redistributiva (talvez socialista, ousemos dizer), acessaram algum direito. Mas populações que se veem hoje em risco vital, punidas por ousarem não apenas dizer seus nomes em histórias de flagelo e exclusão, mas ocuparem os espaços de decisão política e desafiarem o mundo em uma política de ocupação e produção de novas epistemológicas de mundo.

Nossa particularidade nessa cruzada global das renovadas operações do capitalismo deitaram-se facilmente na cama colonial que ainda guardamos nas casas grandes (entre elas os latifúndios demarcados nas instituições públicas como ministérios públicos, tribunais, universidade, etc). E, por isso, creio, a nossa política oligarca, nosso familismo tóxico, a estetização hedonista da "vida que importa" (ou de certo ideal de "humano") e os delírios e fome privatista com a qual alguns privilegiados exibem seus presentes de deus (foi deus quem deu, volta e meia vemos um adesivo) e disposição fundamentalista (como já vemos em muros e carros: bíblia sim, constituição não) sejam importantes vetores que exibem não somente o modus operante dos cartéis e das quadrilhas legislativas e judiciárias, através da bancada BBB - boi, bala e bíblia, por exemplo. Considero que esses vetores também atravessam as nossas vidas, em práticas miúdas, inclusive aquela que experienciamos na universidade e no modo como produzimos ciência, como um vírus perigoso, o vírus da colonialidade.

Vem desses desafios a urgência de pensar o que estamos fazendo de nós mesmXs, como movimento de fazer fugir e escapar, como dissidência e como uma sorte de des(a)fiamento político-científico-epistemológico engendrado na pluralidade cultural e nas tramas das 
infinitas e complexas redes de desigualdade que nos interpelam nos cotidianos de nossas vidas.

\section{A GRAMÁTICA CIENTÍFICA DA (NEO)COLONIALIDADE}

É preciso engordar a crítica às capitanias de nossos dias, pois não nos faltam indícios de nossas distintas oligarquias acadêmicas, muitas delas expressas nos grupelhos que se colocam como eixos de referência epistemológica, alinhados a uma contingência da atual política científica global que pressupõe impacto em um quadro de reconhecimento que não reflete os clamores da agonística social que diz respeito ao enfrentamento às desigualdades e ao extermínio de populações inteiras, que fale e sirva para as gentes consideradas menores nesse país.

Nesse jogo performativo, o conhecimento e o enquadramento teórico-científico ${ }^{3}$ produzem realidades que esses mesmos centros de privilégio continuam forjando. A gramática da colonialidade acadêmica por vezes faz-se rizível, seja por sua métrica do resultado (que descontextualizada nada mais é do que mais um delírio do cálculo neoliberal), seja pelo assenhoramento dos espaços-tempos-sujeitos de conhecimento. Costumam dizer: meu objeto, meus sujeitos, meu campo, meus resultados, meu... eu - senhor/a do conhecimento que pesa e 'impacta'.

Pelos motivos expostos acima acredito que temos o dever de ampliar nossos esforços na continuidade do exame ético radical sobre o que fazemos também no cotidiano acadêmico, facilmente suscetível aos apelos do modo indivíduo e da privataria. Vulnerável e precarizada, a educação pública encontra-se exposta às paixões normativas e fascistas. Precisamos garantir que a universidade continue pública, gratuita e que favoreça o acesso de populações subalternizadas e historicamente excluídas. Mas não somente isso. Faz importante prosseguir na virada epistemológica que muitXs vêm empreendendo (e que não o outro dos movimentos sociais, mas o mais um na rede de solidariedade de muitas lutas). Nós não andamos sós, dizem as companheiras feministas. Mas a política científica neoliberal pode nos separar e a vaidade pode nos enlouquecer.

\footnotetext{
3 Faço uso da extensão científico, pois o espaço acadêmico não é o único lugar de produção de teoria/ teorizações. Sobre essa aposta, ver bell hooks (2013). Além disso, a aposta deste ensaio sugere a noção de epistemologias outras, in mundo, como forma de localizar modos outros de pensar-sentir-viver-perceberconhecer.
} 
Assim, reafirmo, não posso crer que tenhamos condições de repensarmos quais são efetivamente nossos desafios para manter viva a democracia sem que radicalmente venhamos nos comprometer com ela no cotidiano, sem que nossas apostas epistemológicas se embriaguem para uma orgia democrático-participativa... a misturar corpos-vidas-sentidos, sem tutelar o devir, sem tentar dobrar o outro ao meu desejo de liberdade. Antes de querer emancipar a outrem ou dizer o que precisam, devemos pensar em dissipar os (por vezes até inconscientes) desejos de tornar o outro algo semelhante e refém de um dado conhecimento (aqui a funcionar como marcação da diferença). Somos corpolítica desse tempo, governados e tentando governar outrem.

Entendo ainda que a universidade pode cada vez mais estar presente na produção de política pública, com seu conhecimento situado, articulado, de forma a garantir que a correlação de forças que se estabelece a partir da formulação de uma dada política seja marcada pelo exercício da experimentação política, não aquilo que se encerre em programas de tutela política ou que corrobore para a (re)produção da diferença letalizada. Minha aposta consiste em que a política pública, qualquer que seja ela, sempre e incondicionalmente, é um artefato cultural político, maquinaria de inscrição e produção de sentidos - a movimentar diversificadas pedagogias propondo e/ou informando algo na/da/sobre a produção de modos de vida e regulação das instituições e produzindo efeitos em suas práticas.

Por esse motivo, o clamor de que os sujeitos da diferença (fixada, tornada letal) devem estar mais e mais presentes na universidade, como forma de reverter ou alargar minimamente as condições para que se desafie tanto a produção do conhecimento, quanto a formação de profissionais que podem ter na universidade possibilidades de experimentação política em direção à democracia.

Pesquisar tem aqui o sentido amplo de também ser sempre intervenção (e invenção, invenção de margens de compreensão, de ferramentas para pensar como se produz um determinado problema, como algo se torna um problema e como esse problema se materializa em práticas autorizadas, como o racismo, transfeminicídio, a patologização da diferença).

Diante desse quadro agonístico se define para mim aqui uma ontologia política do que penso ser a cidadania: como uma prática cotidiana da/ na universidade, na formação de profissionais que passam pela universidade e que têm a chance de ter suas vidas transtornadas pelo direito à liberdade de pensamento, crítica, invenção. 
Nessas tramas do poder produz-se uma marca indelével sobre o sentido do educar e pesquisar para sua época, lugar e cultura - estabelecendo os limites da participação social e da democracia como uma disputa constante - materializada no tipo de conhecimento que pode circular, o que pode e/ou quem estaria autorizado a produzir e a movimentar esses conhecimentos... o que significa aqui evidenciar disputas de poder, pois todo conhecimento é desde sempre político, situado, localizado... toda epistemologia e política, a ciência é cultura.

A universidade constitui-se, portanto, arena onde se forjam elementos / verdades que informam e (re)produzem hierarquias, desigualdades, injustiças, exclusão e sofrimento de forma contundente quando, especificamente, atrelados às dimensões gênero-sexuais e racializadas da constituição do conhecimento que forja posições de sujeito.

Muitas feministas e outras vozes dissidentes destacam a dimensão de saber-poder onde currículo e cotidiano se oferecem como espaços de reificação de normas e exclusões (Louro, 2004), apontando para os fluxos micro e macropolíticos de abjeção e do conhecimento situado, reforçando a ideia de que as epistemologias são sempre políticas e que as teorias são por isso performativas, intentam descrever muitas vezes objetos que elas mesmas produzem (Silva, 2000).

Ao mesmo tempo, a universidade se coloca como plano possível de reinvenção dos novos modos de fazer política e desde onde emergem novas subjetividades, engendradas em epistemologias cotidianas insurgentes, desobedientes, impertinentes, plano de experimentação, agenciamento de heterotopias - espaços outros (Foucault, 2009).

O poder é produtivo, já nos advertiu Foucault (1995). Assim, não se trata de pensarmos determinados grupos de sujeitos como espécie de vítimas passivas ou despossuídos de qualquer agência. Ao contrário, trata-se de abraçarmos a noção mesma de agência e micropolíticas cotidianas de resistência - que são insurgentes, negociadas, traficadas em termos contexto-dependentes, como sugere Dagmar Meyer (2012). E temos visto essa potente articulação nas ocupações que aconteceram e ainda vem acontecendo nas escolas públicas, os movimentos de jovens feministas e LGBT, jovens negrXs e indígenas, as artes de fazer política também nas redes, evidenciando a potência e certamente os riscos da cibercultura, um espaco-tempo regulado pela nova racionalidade econômica mundial. 


\section{DIZER A VERDADE PARA DESVER O MUNDO}

Em nosso país, a democracia e a propriedade social não podem ser pensadas sem que nos ocupemos de examinar os termos impostos pelo racismo e pelo sexismo e todos os outros modos de marcação da diferença que viemos aprendendo a desconfiar e desafiar com as políticas epistemológicas dissidentes.

Sem isso, não creio que tenhamos muitas chances de refletir sobre que tipo de conhecimento vale a pena tecer na atualidade, tampouco ponderar sobre os reais efeitos do corpo na produção do conhecimento. Penso ainda que é preciso cada vez mais seguirmos nesse horizonte ético que marca posições como aquelas formuladas na esteira das movimentações dissidentes (trans/feministas queer, decoloniais, interserccionais), de modo a firmarmos os termos de produção de conhecimento abjeto ou epistemologias abjetadas aquelas que vieram sendo expurgadas do campo científico, como se fossem excentricidades inúteis (ou desobedientes aos cânones científicos).

Nesse sentido, novamente descontente com as taxonomias acadêmicas, penso que a força engendrada por esses estudos que colocaram o corpo, a subjetividade, como questão central, possa ser uma de nossas linhas de fuga para o instante. Mas até que se apresente outra. Pois quando ela se tornar um programa político-epistemológico ou cânone científico (ou norma), já não mais nos servirá, não será boa para as lutas que precisaremos enfrentar (e que nunca cessarão; e, reforço, não pode sucumbir ao delírio da emancipação como libertação que alucina o poder localizado em instituições).

A potência dessas formas dissidentes, como queer, transfeminismos, decolonialidades (ou algo que anda por essas bandas da 'imundice' epistemológica-cultural) está no devir, em devir, em permitir que possamos a partir de um lance político, de uma jogada, de uma ocupação, escapar, fazer fugir, estabelecendo outros horizontes éticos, estéticos e políticos, ainda não praticados-vividos. E, mesmo que o tenham sido já praticados-vividos, que se reatualizem em versão refletida, praticados no exercício da ética refletida, exercício da liberdade reflexiva (Foucault, 1995), como experimentação do desfazimento e reposicionamento cotidianos. Conhecimento in-mundo, imundo, como experimentação, fruição política na direção de novos horizontes éticos.

Apesar de certa tendência prescritiva nesse meu apelo (afinal a gente sempre pode escorregar no desejo de tentar estabelecer caminhos), não tenho condições de dizer a vocês 
como as coisas devem ser feitas, por dois princípios básicos que tenho tentado sustentar (e a duras penas): o primeiro deles é tentar não sucumbir à vontade deliberada de conduzir o desejo e a vontade política das outras pessoas, embora estejamos quase sempre fazendo isso e o tempo todo (não somente porque nem sempre nos damos conta de nossos privilégios, mas porque isso faz parte do jogo da governamentalidade (Foucault, 2012/1984), sendo uma das condições de nosso modo de operar na agonística social da democracia; o "antídoto" está em percebermos qual margem de liberdade asseguramos nessa disputa para que o jogo seja jogado). Segundo, porque, seguindo o rastro foucaultiano (mas não só, e talvez a poesia, o cinema e a narrativa literária me ajudem mais, como cartografias do nosso tempo), gostaria que estivéssemos a escrever-falar-produzir para desaparecer, tentando assim escapar às benesses da individualidade neoliberal, impregnada em nossas instituições. Talvez este seja o exercício mais difícil que tenhamos em nossos cotidianos.

Dificilmente podemos nos haver com as contingências em total controle de reflexividade ética, pois algo sempre deslizará, algo sempre poderá ser maior que a nossa vontade (seja pela força de outrem, seja pela força maquínica do inconsciente, seja pelas interpelações de uma determinada racionalidade política qualquer). Resta-nos certa disposição que nos permita ter a coragem de dizer a verdade.

Portanto, nesse exercício ético-reflexivo de dizer a verdade, prossigo despretenciosasmente (atento ainda aos obstáculos da vaidade ou luxúria acadêmica), mas de forma implicada, na movimentação de minhas peças de argumentação sobre algumas apostas desde o lugar de um educador, buscando apenas (des)caminhos para pensar a mim mesmo nesse enquadramento normativo de nossas lutas atuais, tomando as ferramentas do ideal democrático (e sua ampla possibilidade de ampliar seus próprios sentidos) como plataforma de produção da experiência do conhecimento que não sucumbe ao imperativo do conhecimento útil e dócil. Aliás, identificado com uma sorte de fazer pesquisa e docência no cotidiano enquanto política de produção de sentidos abertos à insubordinação e às novas possibilidades de ser-habitar a universidade, arriscando um tipo de conhecimento que imundiça o jogo, os jogos de verdade. Afinal, nos termos de Foucault "Há momentos na vida em que a questão de saber se você pode pensar de forma diferente de como você pensa e perceber-se diferente do que você vê é essencial para continuar pensando" (2012/1984: 15). E, 
arrisco dizer, essa é condição mesma sem a qual não faria sentido seguir pesquisando ou trabalhando como educador, ao menos para mim.

Minha narrativa é assumidamente autobiográfica, mas, como sugere Suely Rolnik (2007:22), texto autobiográfico “desde que entendamos por 'auto', aqui, não a individualidade de uma existência, a do autor, mas a singularidade do modo como atravessam seu corpo as forças de um determinado contexto histórico." Afinal, somos subjetivados em processosfluxos encharcados de mundo, de imundices, estamos sujos de mundo, saberes in-mundos, saberes do mundo que são também todos os saberes - acadêmicos ou não.

Com isso, entendo a política da produção do conhecimento como não colada ao aspecto programático institucional, mas como experimentação política cotidiana e insurgente, des(a)fiada constantemente pelas/ com as epistemologias de mundo (outras, como aquilo que por vezes chamamos de saberes subalternizados ou saberes-fazeres cotidianos).

E, enquanto pesquisador e professor do campo educacional, penso-afirmo que nosso trabalho não é/ nem pode ser aquele de moldar a vontade política dos outros/ das outras, mas de (des)construir com as pessoas com quem cruzamos na vida das problematizações planos de investigação-ação sobre os movimentos ontológicos que definem o humano possível nos contextos onde nos inserimos e, assim, pensarmos o que estamos tentando fazer de nós mesmos e do que estamos tentando fazer dos outros (Foucault, 2001/1984).

Nesse sentido, mais do que formadores, talvez nosso lugar seja de deformadores, como partículas atormentadas de contra-discursos, produzindo em nós mesmos, antes de tudo, modos de desver o mundo, como diz o poeta Manoel de Barros. Este pode ser um horizonte ético. Mas, quanto mais nos aproximamos dessa ideia, parece que ela se move mais para um pouco mais além... O que podemos fazer então é seguir em frente.

\section{GOVERNAR A SI... CORPOLÍTICAS DO COTIDIANO}

Pondero aqui, e em vias de (in)conclusão, sobre a imprescindível necessidade de luta para a abertura a modos de auto-instrumentalização político-pedagógica (ou de uma reflexão ética sobre as formas de governo de nós mesmXs diante das forças que intentam nos governar e de como nós mesmos/as desejamos governar os/as outros/as a partir dessa experiência), no manejo das relações sociais que são feitas/tecidas em gênero, sexualidade e raça. Fundamentalmente aquelas que passam pelas condições de possibilidade institucionais e de 
políticas públicas. Para isso, ciente dos riscos que emergem quando precisamos recorrer a ficção / fabricação das identidades, afinal, o grande desafio é: como fazer política para o devir na cama do regramento normativo e normalizador do estado? A saída, por ora, é "tretar" com a vontade de desejar o desejo do estado, os desejos de norma, as normopatias, o descanso das almas amareladas.

Por certo, resistir não é algo tão fácil assim, muito mais em um estado de exceção. Sabemos, nesse momento, a letra da lei não está do nosso lado, está quase morta para a democracia. O que podemos fazer é continuar perturbando, provocando alergias epistemológicas, culturais, insurgências semióticas do desejo. E isso pede coragem. Coragem que, nos termos de Foucault, é sempre física. É sempre correlação de forças, é sempre correlação de forças no corpo.

O constante movimento de abertura às problematizações sobre o fazer educativoacadêmico e em resposta à produção heterocisnormativa, racista e das desigualdades sociais me parece assim um caminho possível para que possamos construir relações sociais menos arbitrárias e violentas, convocando-nos a outras formas de produção política que precisamos urgentemente fazer proliferar (algumas delas já estão por aí, pelas ruas, nas ocupações, nas ruas, nas redes-ruas, mas ocorrem também no interior das universidades, no dentro-fora da universidade, como no evento que motivou parte deste texto - como uma arena importante da agonística social da diferenca e da democracia).

Se nossas disputas devem acontecer no plano das arenas legislativas e na tentativa de garantir o direito e o compromisso radical com a democracia plural e participativa, quebrando a máquina de captura estatal em seu desejo de tutela e morte; isso, porém, não se faz desacompanhado de ações micropolíticas, nos espaços-tempos cotidianos de nossas vidas por onde temos a chance de revisarmos nossas implicações com a diversidade de condições de possibilidade para que alguém possa existir e decidir sobre seu destino. A escola, a unidade básica de saúde e a univerisidade são apenas alguns destes lugares, mas o são também tantos outros os espaços e territórios de produção de vida, espaços imundos de vida, transbordantes em mundos outros, imundos em corpos, corpos in-mundo(s). Mundos outros que nos permitem imaginar que é possível escapar à norma e aos fluxos da máquina-de-morte ultraneoliberal que está por aqui. 


\section{Nanduty}

ISSN:2317-8590

$A h$, e, antes que alguém nos corte ou roube a palavra, esta que é sempre corpo-produção de sentidos, sigamos em busca de escrevivências de vidas esquecidas ${ }^{4}$, como nos sugere Conceição Evaristo (2017) e perfuremos ou estouremos nós mesmXs esses fluxos com nossas línguas encharcadas de histórias impertinentes, com nossas línguas-linguagens bem molhadas, afectivadoras de novos agenciamentos coletivos de enunciação tesudas de liberdade e prazeres dissidentes da norma.

\section{REFERÊNCIAS}

BUTLER, Judith. 2005. Humain, inhumain. Le travail critique des normes. Entretiens. Paris: Éditions Amsterdam.

CASTEL, Robert. 1997. "A dinâmica dos processos de marginalização: da vulnerabilidade à desfiliação". Caderno CRH, Salvador, n. 26/27, , jan./dez, p. 19-40.

DUMARESQ, Leila. 2016. O cisgênero existe. Disponível em: http://transliteracao.com.br/leiladumaresq/2014/12/o-cisgenero-existe/ Acessado em 20 de junho de 2016.

EVARISTO, Conceição. 2018. Conceição Evaristo: 'minha escrita é contaminada pela condição de mulher negra'. Entrevista concedida a Juliana Domingos de Lima, 26 Mai 2017. Link para matéria: https://www.nexojornal.com.br/entrevista/2017/05/26/Concei\%C3\%A7\%C3\% A3o-Evaristo-\%E2\%80\%98minha-escrita-\%C3\%A9-contaminada-pelacondi\%C3\%A7\%C3\%A3o-de-mulher-negra\%E2\%80\%99 Acessado em 26 de março de 2018.

FOUCAULT, Michel. 2009. Le corps utopique. Les hétérotopies. [1966], [1967]. Paris: Nouvelles éditions lignes.

2001. L'éthique du souci de soi comme pratique de la liberté. [1984]. In: FOUCAULT, Michel. Dits et écrits II, 1976-1988. Paris: Gallimard.

1995. "Sobre a genealogia da ética: uma revisão do trabalho". In: DREYFUS, Hubert e RABINOW, Paul. Michel Foucault: uma trajetória filosófica. Rio de Janeiro: Forense Universitária.

2012. História da Sexualidade II. Uso dos prazeres. [1984] Rio de Janeiro: Graal.

\footnotetext{
${ }^{4}$ Escrevivência que precisa ter seu lugar reconhecido como afirmação de epistemologias do tempo que vivemos e daquilo no que para o que estamos nos tornando.
} 


\section{Nanduty}

ISSN:2317-8590

hooks, bell. 2013. Ensinando a transgredir. A educação como prática da liberdade. São Paulo: Martins Fontes, 2013.

LOURO, Guacira Lopes. 2004. Um corpo estranho. Ensaios sobre sexualidade e teoria queer. Belo Horizonte: Autêntica.

MBEMBE, Achille. 2016. "Necropolítica". Arte \& Ensaios - Revista do PPGAV/EBA/UFRJ, n. 32, dezembro, pp. 122-151.

MOUFFE, Chantal. 2003. Democracia, cidadania e a questão do pluralismo. Política e Sociedade, N•03-outubro,pp 11-26.

MEYER, Dagmar Estermann. 2012. “Abordagens pós-estruturalistas de pesquisa na interface educação, saúde e gênero: perspectiva metodológica”. In: MEYER, Dagmar Estermann; PARAÍSO, Marlucy (orgs.). Metodologias de Pesquisas Pós-Críticas em Educação. Belo Horizonte: Mazza Editores, p. 47-61.

HALL, Stuart. 2000. "Quem precisa de identidade?” In: SILVA, Tomaz Tadeu. Identidade e diferença. A perspectiva dos Estudos Cultuais. Rio de Janeiro: Vozes.

ROLNIK, Suely 2007. Cartografia sentimental: transformações contemporâneas do desejo. Porto Alegre: Sulina, Editora da UFRGS.

SILVA, Tomaz Tadeu. 2000. "A produção social da identidade e da diferença". In: SILVA, Tomaz Tadeu (org.). Identidade e diferença. A perspectiva dos Estudos Cultuais. Rio de Janeiro: Vozes. 